\title{
A sustentabilidade da vida cotidiana: um estudo das redes sociais de usuários de serviço de saúde mental no município de Santo André (SP, Brasil)
}

\author{
The sustainability of day-to-day life: a study \\ of the social networks of users of mental healthcare service \\ in the municipality of Santo André (SP, Brazil)
}

Melissa Tieko Muramoto ${ }^{1}$ Elisabete Ferreira Mângia ${ }^{1}$

${ }^{1}$ Laboratório Conexões Investigação e Intervenção em Saúde Mental, Curso de Terapia Ocupacional, Faculdade de Medicina, Universidade de São Paulo. Rua Cipotânea 51, Cidade Universitária. 05360-000 São Paulo SP.

melissatieko@usp.br
Abstract Studies into social networks show that relationships have a significant impact on people's lives. When associated with the population suffering from mental disorders, they serve as an important protection factor and a manager of resources and social support. However, studies show that people with mental disorders have impoverished social networks and few significant relationships. In this perspective, this research sought to characterize the social networks of users of NAPS II in Santo André (SP, Brazil). Conducted in 2006, the qualitative research adopted an ethnographic approach and used interviews by topics, participant observation and field notes. The results revealed that the group studied had an impoverished social network; the life histories of the subjects is related to this impoverishment, since the disruptions caused by situations of crisis or institutionalization removed them from the network of relationships, placing them in a situation of social vulnerability. An attempt was made to address the importance of intervention in the relationships and the role of the services in this process.

Key words Mental health, Social support, Community mental healthcare services, Vulnerability, Mental disorders/rehabilitation, Occupational therapy
Resumo Estudos sobre redes sociais demonstram que as relações têm impacto significativo na vida das pessoas. Quando associadas à população com transtorno mental, atuam como fator de proteção importante e gerenciador de recursos e suporte social. Entretanto, estudos apontam que pessoas com transtorno mental apresentam redes sociais empobrecidas e poucas relações significativas. Nesta perspectiva, esta pesquisa teve como objetivo caracterizar as redes sociais de usuários do NAPS II, em Santo André (SP). Realizada em 2006, a pesquisa qualitativa, orientada pela postura etnográfica, utilizou entrevistas por pautas, observação participante e caderno de campo. Os resultados apontaram que o grupo estudado possui rede social empobrecida; a trajetória de vida dos sujeitos está relacionada a esse empobrecimento, uma vez que as rupturas provocadas pelas situações de crise ou de institucionalização os retiram da rede de relações, colocando-os em situação de vulnerabilidade social. Buscou-se discutir a importância da intervenção nas relações e o papel dos serviços nesse processo.

Palavras-chave Saúde mental, Apoio social, Serviços comunitários de saúde mental, Vulnerabilidade, Transtornos mentais/reabilitação, Terapia ocupacional 


\section{Introdução}

Atualmente, a utilização do conceito de redes sociais apresenta crescimento significativo em estudos de campos de saberes variados, e especialmente no campo da saúde. Diversos autores são unânimes ao afirmarem que a integração das pessoas em redes sociais fortes e sustentadoras pode trazer benefícios para a saúde; e ao contrário, a pobreza de relações sociais significantes se configura como fator de risco ${ }^{1-5}$.

Estudos epidemiológicos recentes assinalam que o envolvimento em uma rede social de suporte está relacionado ao aumento da sobrevida de indivíduos após diagnóstico de doença coronariana, acidente vascular cerebral e câncer, além de diminuição da incidência de insônia e da aquisição de hábitos como tabagismo e alcoolismo e também do risco de doenças demenciais ${ }^{3,5}$.

A interação entre os indivíduos implica reciprocidade de atenção e disponibilidade. Ocorre que nos processos de adoecimento os sujeitos se veem impossibilitados de responderem a essa demanda, enfraquecendo assim seus laços sociais e gerando um "círculo vicioso": a enfermidade tende a enfraquecer os laços sociais, e esse enfraquecimento pode resultar na piora das condições de saúde ${ }^{2}$.

Verifica-se que as pessoas que sofrem de doenças crônicas vivenciam esse processo de forma intensificada. Dependendo do tipo de doença e de suas características, a necessidade da existência de uma rede social forte e integrada é ainda maior, não somente pela influência positiva das relações, mas também para garantir que a pessoa possa sair deste "círculo vicioso" que tende sempre a potencializar a enfermidade e o isolamento ${ }^{1}$.

No caso das pessoas com transtorno mental severo, verificam-se redução significativa da quantidade de pessoas que compõem suas redes sociais, geralmente restritas aos familiares e alguns profissionais de saúde, ausência de relações significativas e enfraquecimento da rede de trocas, que contribuem para a formação de redes sociais empobrecidas, configurando-se em fatores de risco para essa população ${ }^{1,5-9}$.

\section{Aprofundamento teórico}

\section{O conceito de redes sociais}

$\mathrm{O}$ conceito de redes sociais surgiu em meados da década de 1950 e tem origem em dois fatores principais: primeiramente, a busca em superar os limites da análise sociológica e das ciências sociais, de cunho estrutural-funcionalista, que, com base nas tradicionais dicotomias indivíduo e sociedade, ação e estrutura, objetividade e subjetividade, entre outras - concebem a realidade social de forma estática, não sendo capazes de apreender as dinâmicas e os processos de mudanças ${ }^{6-8,10-13}$.

O segundo fator principal se refere ao desenvolvimento de métodos matemáticos não quantitativos, tais como a teoria de gráficos e a análise combinatória, adequados à necessidade de descrever ligações entre elementos de um sistema, possibilidade não contemplada pelos tradicionais métodos estatísticos ${ }^{6,8,14}$.

O conceito de redes sociais é polissêmico, não havendo consenso entre os autores do campo sobre sua definição, o que lhe confere concomitantemente uma grande capacidade heurística e uma baixa possibilidade analítica ${ }^{13}$.

\section{O campo da saúde mental e as contribuições das redes sociais}

\section{Redes sociais e saúde mental}

De acordo com Huxley e Thornicroft ${ }^{15}$, a população que sofre de transtornos mentais está entre as mais excluídas socialmente. Martí ${ }^{8}$ aponta que as pessoas com transtornos dessa natureza formam um "coletivo vulnerável" e transitam por diferentes modalidades de exclusão relacional.

A eclosão de um transtorno mental tende a ocasionar importantes fraturas relacionais, assim como as situações de asilamento hospitalar e a dependência e/ou institucionalização em relação aos serviços de saúde. Tais situações imprimem mudanças significativas na vida relacional e promovem o aumento da vulnerabilidade social desses sujeitos. Estudos demonstram que pacientes com transtornos mentais severos são quatro vezes mais propensos que a média da população a não terem um amigo mais próximo, e mais de um terço deles relatam não ter ninguém a quem recorrer num momento de crise ${ }^{15}$.

No contexto familiar, a presença de uma pessoa com transtorno mental tende a criar situações críticas que mobilizam todos os atores no processo de busca de soluções, tanto dirigidos ao sujeito que sofre como ao próprio grupo do qual ele faz parte, de forma que as redes sociais têm um papel na identificação do problema e também na busca de solução e escolhas terapêuticas. Nesse processo, percebem-se rearranjos, 
rupturas, dissolução e reconfiguração das redes sociais, pois as situações decorrentes dos transtornos mentais, especialmente aqueles severos e persistentes, podem trazer mudanças significativas nas trajetórias de vida da pessoa e em seu circuito relacional ${ }^{6,16}$. De acordo com Starace e Gritti $^{9}$, as modificações mais dramáticas na rede social de pacientes esquizofrênicos acontecem depois da primeira hospitalização, como conseqüência da marginalização, do processo de isolamento e redução da competência social. Neste sentido, a esquizofrenia pode ser interpretada como uma crise na rede relacional à qual o indivíduo pertence.

Observa-se que as redes sociais de pessoas com distúrbios mentais são caracterizadas por serem mais reduzidas se comparadas às de pessoas sem transtornos dessa natureza. Essa redução pode ser visualizada em todas as dimensões da rede, o que aponta para um empobrecimento generalizado de relações e trocas afetivas e materiais ${ }^{9}$. Tal processo tem início antes do aparecimento dos primeiros sinais da doença, aumentando durante o processo psicopatológico e de tratamento. Com frequência, as redes acabam sendo compostas por apenas um tipo de relações, geralmente são limitadas aos laços familiares, caracterizadas por falta de reciprocidade de procura e reconhecimento, e comumente incluem trabalhadores do serviço de saúde mental. Avalia-se que pessoas com esquizofrenia tenham a rede social reduzida a $1 / 3$ do tamanho da rede estimada para indivíduos que não apresentam transtorno ${ }^{6,9}$.

As pessoas com transtorno mental severo apresentam a rede social reduzida em quantidade de laços e qualidade das relações. Verifica-se neste grupo redes compostas, em média, por 70\% de familiares que coabitam com os sujeitos e parentes. Já na população comum, os familiares representam $50 \%$ da rede social ${ }^{13,15}$. Starace e Gritti ${ }^{9}$ afirmam que pessoas que têm sua rede social reduzida à esfera familiar, ou que passam mais de 35 horas por semana em convivência direta com seus familiares, têm 70\% de probabilidade de recaídas ou reinternações. Já entre aquelas que dispõem de outros contatos e relações, passando menos tempo com suas famílias, as recaídas acontecem em menos de 30\% dos casos.

Há diferenças consideráveis entre a rede social dos sujeitos em situação de primeira internação e a rede de pacientes com longos processos de institucionalização. Os primeiros mostraram redes mais amplas e ricas em interconexões, além de maior número de relações múltiplas e independentes. Nesse sentido, estimar o tamanho da rede social e conhecer a qualidade das relações das pessoas com sofrimento psíquico se torna importante, na medida em que o amplo cenário de trocas materiais e afetivas pode favorecer a trajetória de reabilitação desses sujeitos, agindo como fator de proteção e suporte nos momentos de crise e diminuindo o fator de vulnerabilidade social produzido por uma rede social empobrecida ${ }^{6,9}$. Esse empobrecimento generalizado e a carência de relações fortes e/ou íntimas são considerados fatores de risco, pois, de acordo com Souza ${ }^{6}$, quanto mais forte um laço social, maior será a probabilidade de que funcione como apoio, bem como tende a aumentar o auxílio que se pode obter por seu intermédio. Além disso, uma rede social ampla, que inclua relações fortes e frágeis, aumenta a possibilidade de acesso a outras redes, ampliando o rol de recursos e a variedade de informações quando se busca ajuda.

Diversos estudos mostram que pessoas com transtornos mentais severos e persistentes que dispõem de rede social ampla apresentam maior probabilidade de êxitos positivos, em breves ou curtos períodos, nas áreas clínica, laborativa e relacional. Demonstram também que a associação entre rede social e êxito é forte e persistente no tempo, independentemente de outros fatores prognósticos. Pessoas com esse tipo de transtorno, quando inseridas em redes fortemente interconectadas, adiam a busca por ajuda profissional, uma vez que as relações são capazes de lhes fornecer mais apoio social ${ }^{6,17-29}$.

Kinoshita $^{30}$ afirma que a pessoa com transtorno mental se encontra desprovida de poder contratual para participar dos processos de intercâmbio, em três dimensões consideradas fundamentais: troca de bens, troca de mensagens e troca de afetos. Saraceno ${ }^{17,31}$, por sua vez, considera como cenários fundamentais da produção e reprodução da vida social: o morar, o trocar identidades e o produzir e trocar mercadorias e valores. De acordo com esses autores, a pessoa que vivencia a experiência de sofrimento psíquico tende a perder a contratualidade social nesses cenários e, portanto, manter-se excluída dos processos de interação e trocas sociais.

Nesse sentido, é importante discutir e identificar as possibilidades e estratégias que possam conferir sustentabilidade à vida das pessoas fora dos circuitos psiquiátricos. Segundo Saraceno ${ }^{31}$, o processo de reabilitação seria, então, um processo de reconstrução, um exercício pleno da cidadania e, também, de plena contratualidade nos três grandes cenários: habitat, rede social e trabalho com valor social, rompendo com a lógica da ex- 
clusão e segregação social comuns à dinâmica asilar e aos circuitos psiquiátricos.

A utilização dos elementos ou evidências encontrados nos estudos sobre redes sociais pode trazer contribuições importantes para o aprimoramento dos serviços de saúde mental e das estratégias utilizadas no contexto dos projetos de reabilitação psicossocial ${ }^{8,14}$. Novas proposições sobre o desenvolvimento de projetos terapêuticos devem permitir a compreensão da problemática das populações vulneráveis, no contexto de suas redes relacionais, e a identificação, na dinâmica das relações, dos componentes que podem contribuir para a melhoria da saúde e da qualidade de vida.

A importância dessa temática deve ser considerada na elaboração e na realização das intervenções assistenciais e de reabilitação psicossocial desenvolvidas pelos serviços de saúde mental, de forma a tornar a intervenção sobre a rede social uma prioridade operativa, pois contribuir para a criação, o fortalecimento e a manutenção de redes sociais pode ser, de fato, determinante para modificar a trajetória dos usuários ${ }^{16,18,19}$.

A implementação de serviços de saúde mental tem exigido o desenvolvimento de novas estratégias de intervenção, que superem as tradicionais abordagens psiquiátricas e psicoterápicas que priorizam a remissão dos sintomas e descontextualizam o sofrimento mental do cotidiano e contexto de vida das pessoas. Nessa perspectiva e de acordo com as novas proposições do campo da prática dos serviços de saúde mental e da reabilitação psicossocial, as intervenções devem complexificar-se e incorporar em suas estratégias o manejo dos fatores de proteção, que são aqueles que garantem aos sujeitos a possibilidade de viver a vida fora dos circuitos de institucionalização e evitam o empobrecimento do mundo relacional, fatores que solidamente resultam na piora dos transtornos mentais ${ }^{17,31,32}$.

\section{Vulnerabilidade social e serviços assistenciais}

Os serviços orientados pelos modelos tradicionais de assistência apresentam baixa capacidade de enfrentamento dos processos de vulnerabilidade dos indivíduos e coletivos aos quais pertence. De um modo geral, se caracterizam pela oferta de procedimentos ou pelo desenvolvimento de relações duais entre profissionais e clientes, oferecendo atenção centrada no indivíduo e abstraída de seu contexto sociorrelacional, de forma que as ações desenvolvidas não propiciam nem apoiam os processos emancipatórios necessários e fundamentais à população atendida ${ }^{4}$.

No que diz respeito às redes pessoais dos sujeitos, com frequência as ações são voltadas para o núcleo denso da rede, ou seja, os laços mais fortes compostos pela família e amigos íntimos. Verifica-se que essas relações, no caso das populações vulneráveis, são passíveis de saturação, o que aumenta a possibilidade de que o indivíduo não encontre respostas para suas necessidades materiais, de informação e emocionais nesse grupo. Essa situação pode aumentar o estresse vivido pela rede e gerar percepções negativas por parte dos atores que a compõem ${ }^{8}$.

Alguns autores analisam esse processo de saturação das famílias de pessoas com transtornos mentais severos identificando situações de estresse como fatores de risco e geradores de um processo de esgotamento das possibilidades de oferta de apoio e suporte por parte da família e de obtenção de ajuda por parte da pessoa que sofre, constituindo o que Martí denominou de "rede estressada"

Quando o sujeito integra uma "rede estressada” e o único mediador para satisfação de necessidades e obtenção de outros recursos é o serviço de atenção, também este corre o risco de ter rapidamente esgotada sua capacidade de resposta, criando a dinâmica da "porta giratória". Essa dinâmica, identificada inicialmente nos Estados Unidos e também conhecida como revolving door, é um fenômeno comumente encontrado em serviços territoriais de saúde e tem sido exaustivamente discutido, especialmente por autores da Reforma Psiquiátrica. Configura-se num movimento de sucessivas internações em hospitais, psiquiátricos ou não, e retornos para o serviço de base territorial, o que prova o fracasso do modelo de saúde ainda predominante, pautado prioritariamente na remissão de sintomas, que empurra os sujeitos para um circuito permanente de novas inserções institucionais, mas sem respostas para suas necessidades. A falta de emancipação dos usuários e a manutenção de um sistema fechado são os fatores que mais contribuem para a reprodução do fenômeno da porta giratória, criando um sistema que em vez de produzir saúde produz cronicidade. Nessa dimensão, o sujeito permanece constantemente na condição de institucionalizado, e as relações de dependência entre sujeito e serviço dificultam o desenvolvimento da autonomia pessoal ${ }^{8,33}$.

Diversos autores defendem a ideia de que as intervenções capazes de responder concomitantemente à vulnerabilidade relacional e ao estresse 
da rede seriam aquelas realizadas com o objetivo de atingir os laços frágeis presentes na rede expandida do indivíduo, pois estes podem atuar como pontes para redes heterogêneas, que disponibilizam novos recursos ${ }^{8,9,34}$. Desta forma, os profissionais e os serviços deveriam ser capazes de incorporar ações que possibilitassem ao sujeito assistido melhorar as relações próximas, no sentido de diminuir o estresse e dificultar a possibilidade de saturação da rede, e especialmente auxiliar na criação de condições para o acesso ou desenvolvimento de novos vínculos, possibilitando o trânsito por outras redes, o aumento da capacidade de obtenção de recursos, apoio social e suporte. Como consequência dessas ações, se esperaria a redução da dependência do sujeito em relação aos serviços e à configuração de redes sociais que ofereçam novas oportunidades ${ }^{8}$.

Martí $^{8}$ defende a ideia de que o trabalho técnico dos profissionais e dos serviços deveria incluir o diagnóstico do território, com a identificação da existência das sub-redes comunitárias e pessoas que possam atuar como mediadores para a obtenção de recursos e apoio social a partir da conexão com outras redes.

\section{Objetivo e metodologia}

Este artigo é parte da pesquisa de mestrado $A$ sustentabilidade da vida cotidiana: um estudo das redes sociais de usuários de serviço de saúde mental no município de Santo André, desenvolvida pelo Programa de Pós-Graduação em Ciências da Reabilitação da Faculdade de Medicina da Universidade de São Paulo.

O objetivo geral proposto pela pesquisa foi conhecer e caracterizar as redes sociais de 25 usuários de um serviço de saúde mental. A pesquisa, de caráter qualitativo, foi metodologicamente orientada pela postura etnográfica, tendo realizado os seguintes procedimentos: pesquisa bibliográfica, entrevistas por pautas, observação participante e construção de caderno de campo. O projeto e o Termo de Consentimento Livre e Esclarecido foram aprovados pela Comissão de Ética para Análise de Projetos de Pesquisa do Hospital das Clínicas da Faculdade de Medicina da USP.

Foram realizadas 25 entrevistas, com usuários em regime de tratamento intensivo, selecionados por randomização. Todas as entrevistas foram realizadas após a apresentação do estudo e dos objetivos da pesquisa, leitura e esclarecimento de dúvidas sobre o termo de consentimento livre e esclarecido e explanação sobre o roteiro de questões para cada usuário. As entrevistas foram gravadas e posteriormente transcritas.

O processo de observação participante no NAPS II e a construção do caderno de campo deram-se durante o ano de 2006. Desenvolvidos conjuntamente com as entrevistas, tiveram como objetivo conhecer os usuários, as rotinas institucionais e os processos desenvolvidos pela equipe técnica. A presença frequente e intensa no serviço possibilitou identificar processos de sociabilidade entre os usuários e os funcionários do NAPS, nem sempre relatados nas entrevistas. Também colheu informações sobre o desenvolvimento dos projetos terapêuticos e as dinâmicas de atendimento aos usuários. No contexto da observação, acreditamos que as conversas com os usuários, especialmente realizadas no espaço da convivência, tiveram como objetivo identificar mudanças em suas rotinas, alterações em suas redes sociais, desenvolvimento de novas relações, possibilitados pelo processo de acompanhamento e reabilitação.

Neste artigo, apresentaremos os resultados parciais sobre a caracterização das redes sociais dos usuários entrevistados.

\section{Caracterização das redes sociais}

A caracterização das redes sociais dos usuários foi elaborada a partir de três aspectos considerados importantes para a compreensão sobre a estrutura e a qualidade das relações vivenciadas. Cada aspecto pode ser subdividido em características específicas, capazes de ampliar o grau de detalhamento das informações e oferecer mais elementos para a discussão.

No Quadro 1, apresentamos o conjunto de aspectos e características estudadas.

\section{Aspectos estruturais}

Dentre os aspectos estruturais da rede, apresentaremos os dados relacionados ao tamanho, à estrutura e à composição das relações.

Quadro 1. Analisadores das redes sociais.

\begin{tabular}{|l|l|l|}
\hline $\begin{array}{c}\text { Aspectos } \\
\text { estruturais }\end{array}$ & \multicolumn{1}{|c|}{$\begin{array}{c}\text { Aspectos } \\
\text { funcionais }\end{array}$} & $\begin{array}{c}\text { Aspectos } \\
\text { contextuais }\end{array}$ \\
\hline Tamanho & Tipos de relações & Dinâmica \\
\hline Estrutura & Conteúdo das relações & \\
\hline Composição & & \\
\hline
\end{tabular}




\section{Tamanho}

No Tabela 1, apresentamos o número de integrantes da rede social nomeados pelo entrevistado. O número total de relações foi identificado pelo pesquisador no trabalho de compilação dos dados.

Podemos observar que o tamanho das redes sociais dos entrevistados é pequeno quando comparado ao tamanho médio das redes sociais de pessoas que não apresentam transtornos mentais, descrito pela literatura consultada. O número médio de relações identificadas é próximo à quantidade de laços fortes presentes na população em geral, que é de 18,5 contatos $^{13}$.

\section{Estrutura}

As redes sociais dos entrevistados configuram-se pela presença de um núcleo denso de relações próximas, composto por membros da família e, em algumas situações, por trabalhadores do NAPS. Observamos que não houve a identificação de vizinhos e amigos no contexto desse núcleo denso ou dentre os laços que podem ser considerados fortes. O contato com vizinhos e amigos se caracteriza por ser esporádico e aleatório, o que coloca tais relações na periferia ex-

Tabela 1. Usuários e número total de pessoas referidas.

\begin{tabular}{lc}
\hline \multicolumn{1}{c}{ Usuário } & Total de pessoas referidas \\
\hline A.P. & 11 \\
A.A.O. & 19 \\
A.S.A. & 16 \\
A.S.S. & 8 \\
A.S.D. & 10 \\
A.S. & 16 \\
A.H.O. & 14 \\
A.M.M. & 8 \\
A.A. & 17 \\
C.L.V. & 7 \\
D.P. & 5 \\
G.R.F. & 19 \\
I.F. & 14 \\
J.R.N. & 21 \\
J.T. & 13 \\
M.E.A. & 24 \\
N.M.S. & 8 \\
N.B. & 14 \\
Q.I.N. & 12 \\
R.B.S. & 7 \\
R.O. & 2 \\
V.L.S. & 16 \\
V.T.L. & 8 \\
W.L.S.S. & 10 \\
W.C.G.N. & 12 \\
\hline
\end{tabular}

pandida das redes identificadas. Nessa zona das redes, pode-se localizar ainda as relações vivenciadas com parentes e outros usuários do serviço.

\section{Composição}

A composição da rede social diz respeito às características comuns compartilhadas entre o ego e as pessoas com quem se relaciona. Observa-se que existe a tendência de que as redes sociais sejam compostas por pessoas com características semelhantes entre si. Essa característica foi parcialmente observada entre os entrevistados de forma que as redes, além de restritas, são compostas basicamente por familiares e cuidadores, mas, ao contrário do que supúnhamos inicialmente, verificamos uma tendência de afastamento e rejeição em relação às outras pessoas que frequentam o NAPS. As entrevistas mostraram que não há relações consideradas significativas entre os usuários do serviço. Neste caso, a identificação com esse outro - as pessoas com transtorno mental - é considerada como fator negativo. Os discursos não mostraram sentimentos de identificação, empatia ou afetividade com os demais usuários.

Acreditamos ser importante ressaltar que o termo ego, no contexto dos estudos sobre redes sociais, é tradicionalmente utilizado para identificar o sujeito cuja rede social está sendo analisada. Esta análise, construída a partir da perspectiva de um sujeito - o ego -, é uma das vertentes mais importantes da pesquisa sobre redes sociais e é denominada por Molina ${ }^{13}$ como estudo das "redes sociais egocentrada". Neste contexto, o termo não faz referência ao conceito de ego oriundo do campo da psicanálise.

\section{Aspectos funcionais}

Como aspectos funcionais, identificamos as características referentes ao tipo de relações e ao conteúdo ou funções exercidas pela rede.

\section{Tipos de relações}

Consideramos cinco tipos de relações para a caracterização das redes sociais dos usuários: núcleo habitacional/família, família expandida, amigos e vizinhos, relações vivenciadas a partir da situação de trabalho e relações vivenciadas a partir da inserção no serviço. Este último aspecto reconhece o serviço como lugar importante de pertencimento dos usuários; nele buscamos identificar que tipo de relações são estabelecidas entre os usuários e demais pessoas que utilizam o serviço, técnicos e trabalhadores da instituição. 
Na Tabela 2, apresentamos o número de pessoas identificadas pelos usuários em cada um dos cinco campos relacionais.

Optamos por apresentar cada tipo de relação separadamente, buscando detalhar as informações e aprofundar reflexões que consideramos relevantes.

\section{Núcleo habitacional/família}

Este item se refere às relações vivenciadas entre as pessoas que residem com os entrevistados e que mantêm entre si um tempo prolongado de convivência. Buscamos identificar algumas características sobre a qualidade das relações vivenciadas entre essas pessoas.

Observamos que sete usuários referiram poder contar com a família para as questões do dia a dia e que conseguem encontrar suporte e obter ajuda nesse espaço. Apontam a importância de seus familiares compreenderem a "doença" e ajudarem tanto nas situações de crise quanto nos momentos de maior estabilidade. Também consideram importante a postura de cuidado adotada pelas famílias. Os relatos desse grupo confirmaram que a família atua como rede social forte, representando o núcleo denso de relações composto pelas pessoas que estão mais próximas do sujeito. Esse núcleo de pessoas ajuda nos momentos de crise e oferece proteção para situações de maior carga afetiva, que geralmente são responsáveis pela desestabilização dos sujeitos mais vulneráveis ${ }^{13}$.

Sete usuários consideram a convivência com os seus familiares como sendo "normal". Aqui, a ideia de normalidade se traduz pela ausência de brigas e conflitos. Os relatos sobre o ambiente familiar sem brigas sugere, muitas vezes, a presença de um distanciamento afetivo entre os entrevistados e os membros da família. Esses usuários procuram ficar mais tempo sozinhos quando estão em casa e dizem que não conversam muito com as pessoas com quem moram. Os relatos não mostraram a postura de cuidado por parte dos familiares. Alguns usuários desse grupo indicaram a percepção de que não são compreendidos pelos seus familiares no que diz respeito ao transtorno e ao tratamento que fazem.

Sete usuários descreveram relações negativas com seus familiares, afirmando vivenciarem uma convivência difícil e carente de situações de apoio

Tabela 2. Tipos de relações.

\begin{tabular}{|c|c|c|c|c|c|c|}
\hline Nome & $\begin{array}{c}\text { Núcleo habitacional/ } \\
\text { família }\end{array}$ & $\begin{array}{l}\text { Família } \\
\text { expandida }\end{array}$ & $\begin{array}{l}\text { Amigos/ } \\
\text { vizinhos }\end{array}$ & Trabalho & $\begin{array}{c}\text { Relações vivenciadas } \\
\text { no serviço }\end{array}$ & $\begin{array}{l}\text { Total de pessoas } \\
\text { referidas }\end{array}$ \\
\hline A.P. & 1 & 2 & 5 & - & 3 & 11 \\
\hline A.A.O. & 5 & 3 & 4 & 2 & 5 & 19 \\
\hline A.S.A. & 7 & 2 & 3 & - & 4 & 16 \\
\hline A.S.S. & 2 & 1 & 4 & - & 1 & 8 \\
\hline A.S.D. & 3 & 4 & - & - & 3 & 10 \\
\hline A.S. & 1 & 6 & 2 & - & 7 & 16 \\
\hline A.H.O. & 5 & - & 2 & - & 7 & 14 \\
\hline A.M.M. & 3 & 1 & 2 & - & 2 & 8 \\
\hline A.A. & 2 & 7 & 4 & - & 4 & 17 \\
\hline C.L.V. & - & 3 & 2 & - & 2 & 7 \\
\hline D.P. & 1 & 3 & - & - & 1 & 5 \\
\hline G.R.F. & 1 & 2 & 12 & - & 4 & 19 \\
\hline I.F. & 9 & 4 & - & - & 1 & 14 \\
\hline J.R.N. & 9 & 5 & 4 & - & 3 & 21 \\
\hline J.T. & 1 & 5 & 3 & - & 4 & 13 \\
\hline M.E.A. & 2 & 6 & 4 & - & 12 & 24 \\
\hline N.M.S. & 2 & 2 & 1 & - & 3 & 8 \\
\hline N.B. & 9 & 2 & 1 & - & 2 & 14 \\
\hline Q.I.N. & 2 & 4 & 1 & 1 & 4 & 12 \\
\hline R.B.S. & 6 & 1 & - & - & - & 7 \\
\hline R.O. & 1 & 1 & - & - & - & 2 \\
\hline V.L.S. & 8 & - & 5 & - & 3 & 16 \\
\hline V.T.L. & 4 & 2 & - & - & 2 & 8 \\
\hline W.L.S.S. & 2 & - & 1 & - & 7 & 10 \\
\hline W.C.G.N. & 2 & 5 & - & - & 4 & 12 \\
\hline
\end{tabular}


e suporte. Foram relatados episódios de brigas, desentendimentos e violência. Todos os usuários desse grupo referiram a falta de compreensão que sentem por parte da família e a não aceitação do transtorno mental. Situações de descaso e não envolvimento nas questões relativas ao acompanhamento de cada sujeito também foram percebidas.

Para exemplificar essa situação, relatamos o caso de uma usuária que retrata a posição de desvalor e a falta de lugar vivenciado na família. Ela mora na casa dos pais, mas não dispõe de nenhum espaço próprio, tal como um quarto ou cama, de forma que, no momento da entrevista, dormia na casa de uma vizinha da família. Isso acontecia desde a sua saída do hospital psiquiátrico onde esteve internada.

Essa situação aponta para o desvalor atribuído às pessoas com transtorno mental e seus efeitos sobre o lugar destinado e ocupado por algumas dessas pessoas. Observamos que as pessoas tendem a perder espaços na casa e na família, conforme suas trajetórias, e os diversos momentos de ruptura vivenciados, especialmente, após as situações de crise, quando os usuários permanecem muito tempo no serviço ou vivenciam períodos de internação. Ao regressarem, frequentemente encontram os seus espaços reduzidos, tanto no plano concreto quanto no plano afetivo.

Os estudos sobre redes sociais identificam que a família se caracteriza por compor o núcleo denso da rede e, por isso, oferece maior potencial para disponibilizar suporte e apoio social. Segundo Molina ${ }^{13}$, são as pessoas com quem podemos contar no cotidiano. Nossa investigação identificou que 17 usuários - incluindo duas pessoas que moram em serviços residenciais e uma que mora em abrigo - não encontram esse tipo de apoio na relação com seus familiares. Nesse sentido, é importante avaliar os demais espaços em que os sujeitos vivenciam suas relações, uma vez que não encontram suporte em sua rede mais próxima.

\section{Família expandida}

A família expandida corresponde aos parentes e familiares do usuário, excetuando-se pais, irmãos, cônjuge e filhos. Foram consideradas nessa esfera as pessoas que não coabitam com o usuário e não exercem uma função específica de cuidador. Nesse campo relacional, encontramos situações mais graves de não envolvimento e distanciamento em relação aos entrevistados. Vinte e dois usuários falaram sobre sua família, sobre irmãos, tios e primos; entretanto, 15 usuários afirmaram não terem uma boa relação com es- ses familiares. Diversas situações comentadas e relatos demonstram grande afastamento desse grupo e um contato bastante empobrecido.

Nesse sentido, percebemos mais claramente a urgência e a importância da proposição de projetos terapêuticos e programas de reabilitação, voltados para a intervenção sobre a inserção dos indivíduos em contextos que lhes proporcionem possibilidades reais de troca, que lhes confiram respostas às mais diversas demandas da vida cotidiana. O universo familiar, como espaço de cuidado daquele que sofre, é um contexto importante a ser trabalhado no processo de acompanhamento das pessoas com transtornos mentais severos.

Sete usuários afirmaram ter um bom contato e relacionamento com os familiares. Destacaram a profundidade das relações e a importância de tais vínculos. Dentre eles, três identificaram pessoas da família expandida como melhores amigos. Afirmaram sempre poder contar com os familiares para os momentos de maior demanda e nomearam essa esfera como espaço potencial para procurar ajuda.

Três usuários não mencionaram familiares ou parentes durante a realização das entrevistas. Dois desses usuários moram com irmãos e as respectivas famílias. Assim, dividem a mesma casa o usuário, os pais, os irmãos, cunhados e sobrinhos.

\section{Amigos e vizinhos}

O terceiro campo relacional a ser desenvolvido diz respeito aos amigos e vizinhos. Pedimos aos entrevistados que nomeassem as pessoas que consideravam amigas, excluindo aquelas pertencentes à família e ao ambiente do serviço de atenção.

Dez dos entrevistados nomearam pessoas com quem conversam com certa frequência. $\mathrm{O}$ conceito de frequência utilizado nas respostas foi bastante elástico; houve desde a referência a contatos semanais a contatos anuais.

A quantidade de laços identificados é pequena, e as descrições apresentadas sobre as relações permitiram observar que apenas dois deles possuem relações recíprocas, de ajuda e procura mútua.

Dois usuários desse grupo nomearam antigos vizinhos como amigos. Relatam que, após a mudança de residência, a frequência de contato com essas pessoas diminuiu consideravelmente, mas ainda as consideram amigas.

Sete usuários afirmaram não terem nenhum amigo. No Quadro 1, é possível constatar que esses usuários experimentam um empobrecimen- 
to considerável de suas redes sociais. Foram as pessoas que, em geral, identificaram a menor quantidade de relações.

Dois usuários desse grupo afirmam que tinham amigos no passado, mas que, após os episódios de crise ou a partir do conhecimento da doença, os amigos se afastaram. No momento da entrevista, consideravam não terem nenhum amigo.

Neste contexto, acreditamos que é apropriada a discussão sobre as trajetórias dos usuários. Os relatos mostram que eles vão perdendo os laços de amizade, as relações vão sendo enfraquecidas na medida em que os processos de ruptura e vulnerabilização dos sujeitos se reproduzem e não encontram o suporte necessário por parte do serviço de atenção e da família.

Cinco usuários nomearam vizinhos como amigos. Nesses casos, entretanto, não observamos haver relações de proximidade e troca como descrevem os autores consultados. Nos relatos desse grupo, pode-se constatar que há o desenvolvimento de relações superficiais, de vizinhança, e não propriamente de amizade. Ao relatarem o contato que fazem com cada "amigo-vizinho", afirmam que este se resume em "oi”, "bom dia”, "boa tarde", quando se encontram por acaso ao entrarem ou saírem de suas casas. Três usuários falaram de pessoas cujos nomes não sabiam, descrevendo-as apenas pela localização das casas.

Três pessoas descreveram relações de amizade mútua que vivenciam no dia a dia com pessoas fora do ambiente doméstico e não decorrentes da inserção no serviço de atenção. Elas apontaram situações nas quais é possível perceber relações de ajuda e suporte, inclusive nos momentos de maior instabilidade.

É possível observar que a participação dos usuários nessas redes promove um importante grau de proteção tanto para situações comuns vivenciadas no cotidiano quanto para aquelas que demandam mais atenção e cuidado. A percepção das relações de ajuda também se mostra importante para a compreensão dos processos de apoio.

Um dos usuários desse grupo relatou poder contar com os vizinhos de diversas formas, através de ajuda econômica, de auxílio para o cuidado dos netos e da filha e de apoio em momentos de maior ruptura decorrentes de estados de instabilidade.

\section{Trabalho}

O trabalho é campo relacional importante, e dentre os usuários entrevistados, apenas três encontram-se em situação ativa de trabalho no momento da entrevista. Dois deles nomearam pessoas com quem convivem e se relacionam no período em que estão trabalhando.

\section{Relações vivenciadas}

\section{a partir da inserção no serviço}

O último campo relacional investigado é possibilitado pela inserção dos sujeitos no serviço de atenção. Observamos que as relações vivenciadas nesse contexto representam papel importante na rede social dos indivíduos. A partir dos relatos e da observação, foi possível notar que tais relações ocupam grande parte do cotidiano relacional dos usuários. Tais contatos acontecem com frequência maior do que aqueles com familiares, amigos e vizinhos. A Tabela 3 apresenta o número de laços existentes com os técnicos, os funcionários e entre os usuários.

Verificamos que os laços existentes entre os usuários e os técnicos configuram-se como os de maior proximidade, uma vez que a maioria dos entrevistados identifica o técnico de referência como primeira pessoa a procurar em caso de demandas, especialmente aquelas relacionadas ao tratamento.

As relações com os funcionários (trabalhadores das áreas de limpeza, administração, cozinha e suporte técnico) foram descritas como tendo caráter mais afetivo. É possível identificar alguns episódios de ajuda proporcionados por essas relações.

A literatura sobre redes sociais salienta a existência da característica de homofilia, ou a tendência a desenvolver relações com pessoas semelhantes. Devido a essa consideração, inicialmente trabalhamos com a hipótese de que o serviço se configurasse num espaço importante de relações, com potencial para produzir a ampliação das redes sociais dos usuários. Entretanto, essa característica foi parcialmente observada entre os entrevistados. Ao contrário do que supúnhamos, verificamos uma tendência de afastamento e rejeição em relação às outras pessoas que frequentam o NAPS. Muitos entrevistados disseram conversar com os demais usuários, mas afirmaram não haver "ninguém em especial", cujos nomes se lembrassem. Alguns usuários afirmaram não estabelecer nenhuma relação com os outros.

As entrevistas mostraram que não há relações consideradas significativas entre os usuários do serviço. Neste caso, a identificação com esse outro - as pessoas com transtorno mental é considerada como fator negativo. Os discursos não mostraram sentimentos de identificação, empatia ou afetividade com os demais usuários. 


\begin{tabular}{|c|c|c|c|c|c|}
\hline \multirow{28}{*}{ 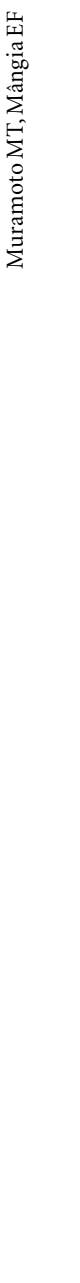 } & Tabela 3. Rel & sivenciadas a partir da inserção n & erviço. & . & \\
\hline & \multirow{2}{*}{ Nome } & \multirow{2}{*}{ Relações vivenciadas no serviço } & \multicolumn{3}{|c|}{ Pessoas referidas } \\
\hline & & & Técnicos & Funcionários & Usuários \\
\hline & A.P. & 3 & 2 & 1 & 0 \\
\hline & A.A.O. & 5 & 2 & 1 & 2 \\
\hline & A.S.A. & 4 & 2 & 1 & 1 \\
\hline & A.S.S. & 1 & 1 & 0 & 0 \\
\hline & A.S.D. & 3 & 2 & 1 & 0 \\
\hline & A.S. & 7 & 1 & 1 & 5 \\
\hline & A.H.O. & 7 & 2 & 0 & 5 \\
\hline & A.M.M. & 2 & 1 & 0 & 1 \\
\hline & A.A. & 4 & 1 & 0 & 3 \\
\hline & C.L.V. & 2 & 0 & 0 & 2 \\
\hline & D.P. & 1 & 0 & 1 & 0 \\
\hline & G.R.F. & 4 & 2 & 1 & 1 \\
\hline & I.F. & 1 & 0 & 0 & 1 \\
\hline & J.R.N. & 3 & 2 & 0 & 1 \\
\hline & J.T. & 4 & 0 & 1 & 3 \\
\hline & M.E.A. & 12 & 3 & 4 & 5 \\
\hline & N.M.S. & 3 & 2 & 1 & 0 \\
\hline & N.B. & 2 & 2 & 0 & 0 \\
\hline & Q.I.N. & 4 & 0 & 1 & 3 \\
\hline & R.B.S. & 0 & 0 & 0 & 0 \\
\hline & R.O. & 0 & 0 & 0 & 0 \\
\hline & V.L.S. & 3 & 1 & 2 & 0 \\
\hline & V.T.L. & 2 & 1 & 0 & 1 \\
\hline & W.L.S.S. & 7 & 4 & 2 & 1 \\
\hline & W.C.G.N. & 4 & 2 & 1 & 1 \\
\hline
\end{tabular}

O estigma ou rejeição ao convívio com o indivíduo com transtorno mental, difuso na sociedade, também aparece como um valor interiorizado pelos próprios usuários, na medida em que estes também buscam evitar o contato com os demais e, quando há contato, procuram fazê-lo com aqueles considerados mais saudáveis.

Notamos que, entre os usuários nomeados pelos entrevistados, aparecem na maioria dos relatos pessoas que ocupam lugar de destaque no serviço. É o que acontece, por exemplo, com a usuária responsável pelo brechó, que foi citada em diversos relatos.

Nenhum dos entrevistados afirmou ter estado na casa de outro usuário, assim como eles disseram não terem sido visitados, mesmo os que estão vinculados ao serviço há muitos anos. Tal fato, associado a outros elementos observados no campo, sugere que tais relações sejam muito frágeis.

\section{Conteúdo das relações}

Buscamos conhecer o tipo de ajuda recebida pelos usuários, quem a oferece e em quais momentos. Dezoito pessoas afirmaram contar com seus familiares para ajuda nas situações cotidianas; apenas cinco pessoas afirmaram procurar os profissionais do serviço. Dentre essas, estão os moradores da residência terapêutica e o usuário que reside em um abrigo. Dois usuários afirmaram não obter ajuda de ninguém.

Nos momentos de crise, apenas os usuários que não moram com familiares afirmaram procurar o NAPS para obter ajuda. Os demais referem que seus familiares são os primeiros a perceber quando não estão bem e a oferecer ajuda.

De acordo com as descrições das relações vivenciadas, é possível apreender que a função de suporte é desempenhada por algumas pessoas e não por toda a rede social. Também percebemos que há poucas relações de confidência e socialização, sendo que apenas três usuários dispõem de amigos cuja relação mostra-se mais significativa. Nesse sentido, o empobrecimento global da rede 
social desses sujeitos aparece mais uma vez como fator de risco, na medida em que as possibilidades de encontrar ajuda e suporte, especialmente para as situações do cotidiano, tornam-se escassas.

\section{Aspectos contextuais}

Os aspectos contextuais dizem respeito à história da rede social. Aqui, apresentaremos os dados relativos à dinâmica e às mudanças ocorridas nas redes sociais dos usuários.

\section{Dinâmica}

Ao longo da vida, ocorrem mudanças nas redes sociais, intensificadas por acontecimentos singulares, tais como internações e momentos de crise. As fraturas relacionais são identificadas como processos que podem levar ao empobrecimento da rede social e colocar o indivíduo em situação de vulnerabilidade relacional. Os transtornos mentais e as diversas rupturas vivenciadas a partir de processos de retirada da pessoa de sua vida cotidiana e de institucionalização são identificados como fraturas relacionais.

Entre as pessoas entrevistadas no NAPS, verificamos que o processo de adoecimento e as diversas rupturas decorrentes produziram mudanças significativas em suas redes sociais. Assim, a eclosão do transtorno, o longo percurso de tratamento, os processos de institucionalização, desde os mais brandos - representados pela presença diária no serviço, mas manutenção parcial da vida doméstica e familiar - até os mais graves, representados pela possível internação, configuram-se em importantes determinantes da redução e do aumento da fragilidade relacional das pessoas com transtornos mentais.

\section{Considerações finais}

O processo de realização da pesquisa demonstrou que os sujeitos estudados apresentam empobrecimento em suas redes sociais e poucas relações consideradas significativas. Confirmando os dados encontrados na literatura sobre redes sociais, foi possível apreender que tais relações são frágeis, pouco capazes de oferecerem suporte social e de agenciarem recursos materiais e afetivos, o que amplia a necessidade de elaboração e desenvolvimento de estratégias e de modalidades de cuidado que possibilitem a intervenção nas redes sociais.

Algumas situações relatadas demonstram a dificuldade em conseguir ajuda da família e apon- tam para o esgotamento da rede social mais próxima. A família esgota sua capacidade de gerar respostas às demandas dos sujeitos, conseguindo apenas satisfazer a algumas necessidades básicas. Essa situação pode ser compreendida como geradora de estresse para todos os componentes envolvidos e é alimentada pelo empobrecimento generalizado das redes sociais dos entrevistados. Tal dinâmica produz situação de saturação que resulta na incapacidade da família em desempenhar a função de suporte.

Identificamos que os entrevistados não dispõem de laços de amizade significativos, o que também contribui para restringir as possibilidades de acesso à ajuda e a outros recursos necessários.

A exclusão no campo do trabalho determina a fragilidade econômica dos usuários e os priva de relações que poderiam surgir nesse contexto. De acordo com o modelo proposto por Castel ${ }^{34}$, podemos caracterizar a população com transtorno mental como ocupante da zona de desfiliação, pois não dispõe de inserção no campo do trabalho e se insere em redes sociais empobrecidas e frágeis. Assim, podemos concluir que essas pessoas vivenciam um duplo processo de exclusão.

Observamos também que existe uma forte relação de dependência institucional, que situa o NAPS em posição análoga à ocupada pela família. O serviço de saúde mental também se configura como principal agenciador de recursos, consequência da falta de acesso a outras redes, e também vê sua capacidade de resposta esgotada devido à sobrecarga de demandas. A existência de relações duais entre usuários e profissionais não é capaz de promover respostas emancipatórias necessárias para a construção da autonomia e da independência das pessoas. Nessa perspectiva, podemos concluir que o serviço não consegue atuar como potencializador para a entrada em novos circuitos de trocas e atua de forma disfuncional, produzindo respostas muito homogêneas e não adequadas às necessidades específicas de cada sujeito.

A pesquisa evidenciou que, na construção dos projetos terapêuticos, o serviço não considera os aspectos referentes à sociabilidade dos usuários, o que determina a impossibilidade de prevenir ou evitar os riscos das transformações negativas ocorridas nas redes pessoais após a eclosão do transtorno mental e das diversas rupturas provocadas pelos processos de institucionalização, além de não promover ações que imprimam mudanças nessa dinâmica. Nesse sentido, consideramos a necessidade de os serviços substitutivos de saúde mental assumirem a vulnerabilidade relacional como alvo das propostas de inter- 
venção. Defendemos a ideia de que as proposições e os modelos apresentados pelos autores e referenciais teóricos aqui citados configuram-se em importantes bases para a construção de políticas públicas nesse setor e para a orientação do trabalho técnico desenvolvido pelos profissionais que atuam nos Caps. Também consideramos que as contribuições trazidas pelos estudos que investigam as redes sociais e os processos de vulnerabilidade social devam ser considerados na construção dos projetos terapêuticos individuais que tenham como objetivo aumentar a contratualidade e o poder de trocas afetivas e materiais das pessoas com transtornos mentais severos.

\section{Colaboradores}

MT Muramoto e EF Mângia participaram igualmente de todas as etapas de elaboração do artigo.

\section{Referências}

1. Andrade GRB, Vaitsman J. Apoio social e redes: conectando solidariedade e saúde. Cien Saude Colet 2002; 7(4):925-934.

2. Chor D, Griep RH, Lopes C, Faerstein E. Medidas de rede e apoio social no Estudo Pró-Saúde: prétestes e estudo piloto. Cad Saude Publica 2001; 17(4):887-896.

3. Griep RH, Chor D, Faerstein E, Lopes C. Confiabilidade teste-reteste de aspectos da rede social no Estudo Pró-Saúde. Rev Saude Publica 2003; 37(3):379385 .

4. Molina JL, Aguilar C. Redes sociales y antropologia: um estudio de caso (discursos étnicos y redes personales entro jóvenes de Sarajevo). Redes - Revista Hispana para Análisis de Redes Sociales [periódico na Internet]. [acessado 2005 jun 3]. Disponível em: http://revista-redes.rediris.es/

5. Sluzky CE. A rede social na prática sistêmica. $3^{\text {a }}$ ed. São Paulo: Casa do Psicólogo; 2006.

6. Souza IM. Na trama da doença: uma discussão sobre redes sociais e doença mental. In: Rabelo MCM, Alves PCB, Souza IMA. Experiência de doença e narrativa. Rio de Janeiro: Editora Fiocruz; 1999. p. 89-124.

7. Mângia EF, Muramoto MT. O estudo de redes sociais: apontamentos teóricos e contribuições para o campo da saúde. Rev Ter Ocup Univ 2005; 16(1):2230.

8. Martí JB. La vulnerabilidad relacional: análisis del fenômeno y pautas de intervención. Redes - Revista Hispana para el Análisis de Redes Sociales [periódico na Internet]. 2006 [acessado 2005 jun 3]; 11(4):[cerca de 1-18 p.]. Disponível em: http://revistaredes.rediris.es/ 
9. Starace F, Gritti P. Social network and social support: experiences and prospects for intervention. Per la Salute Mentale/For Mental Health 1987; 4:211216.

10. Marteleto RM. Análise de redes sociais: aplicação nos estudos e transferência da informação. Ciência da Informação 2001; 30(1):71-81.

11. Martins P, Fontes B. Redes sociais e saúde: novas possibilidades teóricas. Recife: Editora Universitária da UFPE; 2004.

12. Kadushin C. Who benefits from network analisis: ethics of social network research. Social Networks [periódico na Internet]. 2005 [acessado 2009 jan 20]; 27:139-153. Disponível em: www.elsevier.com/ locate/socnet

13. Molina JL. El estudio de las redes personales: contribuciones, métodos y perspectivas. Redes - Revista Hispana para el Análisis de Redes Sociales [periódico na Internet]. 2005 [acessado 2009 jan 20]. Disponível em: http://revista-redes.rediris.es/.

14. Deslandes SF, Mendonça EA. As redes sociais e as representações de risco para usuários de drogas injetáveis [documento na Internet]. 2001 [acessado 2009 jan 20]. Disponível em: www.aids.gov.br/final/ biblioteca/avaliacao6/ajude_71.htm

15. Huxley P, Thornicroft G. Social inclusion, social quality and mental illness. Br J Psychiatry 2003; 182:289-290.

16. Mângia EF. Notas metodológicas para a pesquisa de campo e análise de entrevistas. São Paulo: Lab. Conexões, FMUSP; 2006.

17. Saraceno B. Libertando identidades: da reabilitação psicossocial à cidadania possivel. Rio de Janeiro: Instituto Franco Basaglia; Belo Horizonte: Te Corá; 1999.

18. Terzian E, Tognoni G. Studio randomizzato di intervento sulla rete sociale (SIRS) nei servizi psichiatrici territoriali (SPT). Protocollo, Laboratorio Farmacologia Clinica, Istituto di Ricerche Farmacologiche Mario Negri. Milano: [s.n.]; 2004. (Mimeo).

19. Castelfranchi C. La produzione interpersonale e istituzionale della gravità. In: Attenasio L. (a cura di) Dialogo con la follia: un approccio colletivo al trattamento del paziente grave. Roma: Armando Editore; 2003.

20. Leff J, Trieman N. Long-stay patients discharged from psychiatric hospital: social and clinical outcomes after five years in the community - the TAPS Project 46. Br J Psychiatry 2000; 176:217-223.

21. Becker T, Thornicroft G, Leese M, McCrone P,

21. Johnson S, Albert M, Turner D. Social networks and service use among representative cases of psychosis in South London. Br J Psychiatry 1997; 171(7):15-19.

22. Bedoni A. Un commento agli studi prospettici sull'esito dei disturbi schizofrenici pubblicati negli ultimo 10 anni. Lettera - Percorsi Bibliografici in Psichiatria 1995; 20:96-145.
23. Castelfranchi C. Prevenzione: tra pessimismo della ragione e ottimismo della volontà. In: Piccione R. (a cura di) Prevenzione e salute mentale: fondamenti, pratiche, prospecttive. Roma: Carocci Editore; 1998.

24. Castelfranchi C, Henry P, Pirella A. L'invenzione colletiva. Torino: Edizioni Gruppo Abele; 1995.

25. Hall GB, Nelson G. Social networks, social support, personal empowerment, and the adaptation of psychiatric consumers/survivors: path analytic models. Social Science Med 1996; 43(12):1743-1754.

26. Dayson D, Lee-Jones R, Chahal KK, Leff J. The TAPS Project 32: social network of two group homes... 5 years on. Soc Psychiatry Psychiatr Epidemiol 1998; 33:438-444.

27. Saraceno B. A cidadania como forma de tolerância [conferência]. Rio de Janeiro: [s.n.]; 1998.

28. Howard L, Leese M, Thornicroft G. Social networks and functional status in patients with psychosis. Acta Psychiatr Scand 2000; 102(5):376-385.

29. Bengtsson-Tops A, Hansson L. Clinical and social changes in severely mentally ill individuals admitted to an outpatient psychosis team: an 18-month follow-up study. Scand J Caring Sci 2003; 17:3-11.

30. Kinoshita RT. Contratualidade e reabilitação psicossocial. In: Pitta A. Reabilitação psicossocial no Brasil. 2a ed. São Paulo: Hucitec; 2001. p. 55-59.

31. Saraceno B. Reabilitação psicossocial: uma estratégia para a passagem do milênio. In: Pitta A. Reabilitação psicossocial no Brasil. 2a ed. São Paulo: Hucitec; 2001. p. 13-18.

32. Rotelli F. Re-habilitar la re-habilitación. S.l.: [s.n.]; 1993. (Mimeo).

33. Granovetter MS. The strength of weak ties. JSTOR (Journal Storage) [periórico na Internet]. 1973 [acessado 2009 jan 20]. Disponível em: www.jstor.org

34. Castel R. Da indigência à exclusão, a desfiliação: precariedade do trabalho e vulnerabilidade relacional. In: Lancetti A, organizador. SaúdeLoucura: grupos e coletivos. São Paulo: Hucitec; 1994. p. 21-48.

Artigo apresentado em 01/07/2008

Aprovado em 15/01/2009

Versão final apresentada em 20/02/2009 